\title{
\begin{tabular}{|l|} 
EXPERT \\
\hline REVIEWS \\
\hline
\end{tabular}
}

\section{Aciclovir, herpes viruses and HIV: a never-ending story}

Expert Rev. Anti Infect. Ther. 7(4), 403-407 (2009)

\section{Antonio Volpi ${ }^{\dagger}$, Cesare Sarrecchia and Pasquale Sordillo \\ ${ }^{+}$Author for correspondence Department of Public Health, University of Rome Tor Vergata, Via Montpellier 1, 00133 Roma, Italy \\ Tel.: +390620903440 \\ Fax: +390620903441 \\ volpi@uniroma2.it}

Evaluation of: Delany S, Mlaba N, Clayton T et al. Impact of aciclovir on genital and plasma HIV-1 RNA in HSV-2/HIV-1 co-infected women: a randomized placebo-controlled trial in South Africa. AIDS 23, 461-469 (2009).

HIV infection continues to be among the leading causes of morbidity and mortality, especially in Africa. The prevalence of herpes simplex virus type 2 (HSV-2) has already reached high seroprevalence of up to $90 \%$ in HIV-seropositive individuals, and HSV-2 is now the leading cause of genital ulcer disease in both developing and developed countries. The role of HSV-2 as a biological cofactor in HIV acquisition and transmission may have contributed substantially to HIV diffusion, also facilitating HIV spread among the low-risk population who have stable longterm sexual partnerships. To date, no vaccine to prevent HSV-2 acquisition or reactivation has been developed, although antivirals have been shown to be safe and effective in reducing HSV-2 shedding frequency and the duration of genital ulcer disease. The paper under evaluation confirms the favorable effect of therapies aimed at suppressing HSV-2 reactivation in HIVseropositive patients on HIV plasma and vaginal load. In this study, aciclovir 400 mg twice daily was able to significantly reduce plasma and genital HIV RNA, the frequency of HIV shedding, genital HSV-2 DNA and the frequency of genital ulcerations. These results suggest that HSV-2 control with low-cost aciclovir can play an important role in reducing HIV spread, mainly in developing countries, where costs limit the use of highly active antiretroviral therapy.

KEYWORDS: aciclovir $\bullet$ HIV $\bullet$ HIV transmission $\bullet$ HSV

The present manuscript reviews the study of Delany et al. on the impact of herpes simplex virus type 2 (HSV-2) suppressive aciclovir on genital and plasma HIV-RNA in 269 HSV-2/ HIV-coinfected women in South Africa [1]. HIV infection continues to be among the leading causes of global morbidity and mortality, especially in Africa. An estimated 40 million people are HIV positive with an annual mortality of 3 million. The rapid spread of HIV as a sexually transmitted infection (STI) is exceeded by that of HSV-2 [2-4]. The chronic nature of HSV-2 infection with frequent and mostly unrecognized reactivations [5,6], and its relatively large transmission probability per coital act $[7,8]$, leads to HSV-2 having a different epidemiology from STIs. Indeed, the prevalence of HSV-2 has already reached high seroprevalence, of up to $90 \%$ in HIV-positive patients, and HSV-2 is now the leading cause of genital ulcer disease (GUD) in both developing and developed countries $[2,4,9,10]$. The epidemiological data indicate that HIV and HSV-2 have overlapping prevalence patterns around the globe [11-15]. The epidemiological overlap between the two viruses, as well as the nature of HSV-2 infection as a leading cause of clinical and subclinical genital ulceration and mucosal disruption, have suggested a role for HSV-2 in the elevation of the HIV pandemic since the late 1980s [16]. Two systematic reviews of 18 longitudinal studies showed that HSV-2 seropositivity has a relative risk of 2 or higher for HIV acquisition, after controlling for sexual behavior $[17,18]$. These epidemiologic observations have been corroborated by evidence of biological plausibility. CD 4+ lymphocytes, HIV target cells, have been detected in herpetic lesions $[19,20]$, which could increase HIV susceptibility during sexual exposure, and evidence was obtained that the same cells can produce in vitro HIV pseudotyped by the HSV-1 envelope [21]. Furthermore, the evidence that HSV-2 increases HIV transcription in vitro [22-26] potentially explains the high levels of HIV RNA seen in herpetic lesions [27] and in plasma in dually infected patients [28-30], and supports higher HIV infectivity in dually infected individuals [31]. This has been corroborated by epidemiologic studies that suggested a 
relative risk of two- to five-fold of transmitting HIV from individuals coinfected with HSV-2 compared with individuals who are HSV-2 seronegative [32,33]. In addition, HIV infection has been shown to substantially increase mucosal HSV-2 shedding [34-40]. These observations led to several proof-of-concept, placebo-controlled trials to assess the effect of HSV-2 suppression on HIV infectiousness.

\section{Methods}

The authors recruited 300 women out of the 583 screened from the community or from support groups for people living with HIV/AIDS in Johannesburg, South Africa. The eligibility criteria were: age 18 years or older; HIV and HSV-2 seropositivity; clinically asymptomatic for HIV, according to WHO criteria [41]; a CD4 cell count of at least $250 \mathrm{cells} / \mathrm{ml}$; negative urine pregnancy test; not breastfeeding; and no contraindication to aciclovir suppressive therapy.

Participants were randomized 1:1 to aciclovir $400 \mathrm{mg}$ twice daily or matching placebo. Following randomization, participants were seen at monthly clinic visits for a total of three visits (M1, M2 and M3). Information on symptoms, adverse events and adherence was obtained and blood and genital samples were collected. All participants received pretest and post-test STI/HIV counseling, regular risk-reduction counseling, free condoms, treatment of laboratorydiagnosed STIs and STI syndromes, and referral to local HIV treatment centers. GUD episodes were treated presumptively as genital herpes with aciclovir $400 \mathrm{mg}$ three-times daily for 5 days, irrespective of study group. A standardized cervico-vaginal lavage $(\mathrm{CVL})$ was performed at all visits for the measurements of genital HIV and HSV-2 shedding. The primary outcomes of the trial were the detection and quantity of genital HIV RNA in CVL at M3. Secondary outcomes included quantity of plasma HIV RNA $\left(\log _{10}\right.$ copies $\left./ \mathrm{ml}\right), \mathrm{CD} 4$ cell count, detection and quantity of genital HSV-2 DNA in CVL, and occurrence of GUD episodes.

\section{Results}

Results from 269 (90\%) participants (132 aciclovir and 137 placebo) out of 300 randomized individuals were available for inclusion in the primary analysis of outcomes at the M3 visit and 288 (96\%) participants (146 aciclovir and 142 placebo) for the summary and repeat measures analyses.

Overall, 541 out of $604(90 \%)$ and 545 out of $592(92 \%)$ of the planned clinic visits were completed by participants in the aciclovir and placebo groups, respectively. There was no association between treatment arm and missed visits. The treatment groups were well balanced for most baseline characteristics. Across the two enrolment visits, there were similar proportions of persistent HIV shedders in the aciclovir and placebo groups (42 vs $41 \%$ ). The proportion of HIV/HSV-2 shedders was similar in the two groups (30 vs $28 \%$ ). The proportion of women with detectable genital HIV RNA was consistently lower in the aciclovir group. Using summary measures analysis, there was evidence for a strong effect of aciclovir in reducing the frequency of HIV shedding among women (adjusted odds ratio [OR]: 0.57; 95\% CI: $0.36-0.89 ; \mathrm{p}=0.013)$. Among women with detectable genital
HIV, the mean quantity of HIV RNA was lower in the aciclovir group $\left(-0.13 \log _{10}\right.$ copies $/ \mathrm{ml}$; $\left.95 \% \mathrm{CI}:-0.28-0.03\right)$, although the evidence for a difference was weak $(\mathrm{p}=0.12)$. Significant reductions in M3 plasma HIV RNA $\left(-0.34 \log _{10}\right.$ copies $/ \mathrm{ml}$; $95 \%$ CI: -0.54 to $-0.15 ; \mathrm{p}<0.001)$, A similar result was observed when all four follow-up visits were included. There was a reduction of $0.27 \log _{10}$ copies/ml (95\% CI: 0.13-0.41; p < 0.001) across all visits, equivalent to a $46 \%$ reduction in mean HIV plasma viral load. Significant reductions in genital HSV-2 DNA (8 vs $20 \%$; relative risk [RR]: 0.37 ; $95 \%$ CI: $0.19-0.73$ ) and genital ulceration (8 vs $18 \%$; RR: 0.43 ; $95 \%$ CI: $0.22-0.84$ ) were also observed in the aciclovir group.

\section{Discussion}

Although the present report and other smaller trials conducted among women in Burkina Faso and Thailand, and one conducted among homosexual men in Peru, have shown reductions in plasma and genital or rectal HIV viral loads using aciclovir or valaciclovir [42,43], two recently published randomized controlled trials have shown that daily aciclovir does not reduce the risk of HIV acquisition in HSV-2 seropositive, HIV-seronegative individuals. The necessary reduction in the frequency of genital HIV RNA shedding in order to reduce sexual transmission of HIV is unclear. Clinical assessment of HSV-2 disease severity, as defined by the number of recurrences, appears to be a poor predictor of the risk of transmission to sexual partners [44]. Although individuals with frequent recurrences are most likely to benefit clinically from suppressive antiviral therapy, they do not appear to have any higher risk of transmission than those with less frequent recurrences. As aciclovir suppressive therapy was evaluated as a means of reducing HIV transmission, it is also likely that HIV transmission can be independent of the frequency of HSV-2 recurrences [44].

The present research was conducted as an intention-to-treat study without reporting clinical failures of the suppressive therapy or looking for aciclovir-resistant strains. To our knowledge, the prevalence of aciclovir-resistant strains in immunocompetent and HIV patients in Africa is not known and, unfortunately, it was not evaluated in these studies. It is likely to be quite high among HIV patients, reducing the effect of the suppressive therapy at population level. It is known that aciclovir-resistant HSV can emerge rapidly during the course of antiviral therapy in immunocompromised patients [45]. Moreover, a continuing survey of HSV isolates from HIV-positive patients in the USA and Canada from 1998 to 2000 indicates that the prevalence of resistant HSV is approximately $6 \%[46]$. In addition, it is worth mentioning that in a recent study in immunocompetent women, aciclovir-sensitive and aciclovir-resistant isolates were detected in samples collected on the same day from separate anatomic sites in three women [47]. In that study, the recovery of aciclovir-resistant HSV-2 isolates was obtained during both symptomatic recurrences of genital herpes and episodes of subclinical shedding. Moreover, the lack of a complete correlation between in vitro susceptibility of viral isolates and clinical response implicates other factors in the clinical outcome. These include the antiviral medication (dose, dose frequency, 
route of administration and level of compliance), absorption and metabolism of the antiviral, immunological response of the patient and heterogeneity of the virus population [45]. Hence, data on HIV viral load in the blood or at genital level during HSV-2 suppressive therapy with aciclovir could be underestimated by the presence of aciclovir-resistant strains or reduced intestinal absorption of aciclovir in this population.

An interesting point is that it is likely that now we have the answer to a long-standing controversy: in the early 1990s, some clinical studies indicated that aciclovir, combined with zidovudine, improves survival time for HIV-infected individuals, although exactly how aciclovir prolongs survival was not known [48,49]. A $26 \%$ decrease in the risk of death was obtained in persons taking both aciclovir and zidovudine. If aciclovir treatment was initiated after a clinical diagnosis of AIDS, the risk of death was reduced by $44 \%$ [49]. At that time, those risk reductions were roughly equivalent to an increased survival time of 6 months to 1 year. Some researchers hypothesized that herpes viruses were cofactors in the progression of HIV disease and that aciclovir was suppressing herpes infections. However, even if studies using both highdose aciclovir and aciclovir at a dose sufficient to suppress HSV recurrences (i.e., $600-800 \mathrm{mg} /$ day) as a cotherapy to zidovudine had a clinically significant effect on prolonging survival in some cohorts of HIV-infected patients [49], it was thought that levels of aciclovir suppressing also cytomegalovirus (CMV) could obtain better survival. To this purpose valaciclovir $8 \mathrm{~g} / \mathrm{day}$, the prodrug of aciclovir with better bioavailability, was compared with aciclovir, 3.2 or $0.8 \mathrm{~g} /$ day, for CMV prevention; and all three arms were compared for survival. Valaciclovir significantly reduced the risk of CMV disease, but a trend toward earlier mortality for valaciclovir recipients was seen [50]. Now we can say that it is likely that the prolonged survival in patients on aciclovir was due to a reduced HIV load, attained due to HSV suppression. When highly active antiretroviral therapy was introduced, this modest, but important effect was obscured by the HIV suppression by antiretrovirals [51].

\section{Expert commentary \& five-year view}

The role of HSV-2 as a biological cofactor in HIV acquisition and transmission may have contributed substantially to HIV, particularly by facilitating HIV spread. This finding suggests that control of HSV-2 infection may be an effective intervention in reducing HIV spread in Africa. Our current tools for reducing the impact of HSV-2, such as the use of HSV-specific antivirals such as aciclovir to suppress HSV-2 reactivation, may not be effective enough to reduce the effect of HSV-2 on increasing HIV susceptibility, which contributes to the HSV-HIV synergy. However, a HSV-2 vaccine may be an effective intervention for preventing the interaction of the two infections by removing HSV-2 as a risk factor for HIV acquisition and transmission.

A few years ago, studies suggested that the glycoprotein $D$ vaccine has efficacy against genital herpes in women who are seronegative for both HSV-1 and HSV-2 at baseline. Unfortunately, it had no efficacy in women seropositive for HSV-1 and seronegative for HSV-2, or in men, regardless of their HSV serologic status [52]. At present, a number of herpes vaccines are under development and we hope to have an efficient vaccine available in the next few years.

\section{Financial \& competing interests disclosure}

The authors have no relevant affliations or financial involvement with any organization or entity with a financial interest in or financial conflict with the subject matter or materials discussed in the manuscript. This includes employment, consultancies, honoraria, stock ownership or options, expert testimony, grants or patents received or pending, or royalties.

No writing assistance was utilized in the production of this manuscript.

\section{Key issues}

- The prominent effect of herpes simplex virus type 2 (HSV-2) in facilitating the spread of HIV epidemic in sub-Saharan Africa is related to:

- The biology of HSV-2 as a chronic infection and a leading cause of clinical and subclinical genital ulcers

- The high HSV-2 prevalence

- Enhanced HIV acquisition in HSV-2-seropositive individuals

- Enhanced HIV infectivity in dually infected subjects

- HSV-2 suppressive therapy with aciclovir reduces HIV-1 plasma viral load and alters the pattern of genital HIV-1 shedding.

- HSV-2 suppressive therapy with aciclovir or valaciclovir does not appear to reduce HIV acquisition in some studies in Africa. Adherence, absorption and HSV-2 resistance can account for these negative results.

- A HSV-2 vaccine could limit the genital herpes epidemic and reduce the spread of HIV infection.

\section{References}

-1 Delany S, Mlaba N, Clayton T et al. Impact of aciclovir on genital and plasma HIV-1 RNA in HSV-2/HIV-1 co-infected women: a randomized placebo-controlled trial in South Africa. AIDS 23, 461-469 (2009).

- O'Farrell N. Increasing prevalence of genital herpes in developing countries: implications for heterosexual HIV transmission and STI control programmes. Sex. Transm. Infect. 75, 377-384 (1999).

- 3 Smith JS, Robinson NJ. Age-specific prevalence of infection with herpes simplex virus types 2 and 1: a global review. J. Infect. Dis. 186(Suppl. 1), S3-S28 (2002).
4 Weiss H. Epidemiology of herpes simplex virus type 2 infection in the developing world. Herpes 11(Suppl. 1), 24A-35A (2004).

-5 Wald A, Zeh J, Selke S et al. Reactivation of genital herpes simplex virus type 2 infection in asymptomatic seropositive persons. N. Engl. J. Med. 342, 844-850 (2000). 
-6 Benedetti J, Corey L, Ashley R. Recurrence ${ }_{18}$ rates in genital herpes after symptomatic first-episode infection. Ann. Intern. Med. 121, 847-854 (1994).

7 Wald A, Langenberg AG, Link K et al. Effect of condoms on reducing the transmission of herpes simplex virus type 2 from men to women. JAMA 285, 3100-3106 (2001).

$>_{8}$ Wald A, Krantz E, Selke S et al. Knowledge of partners' genital herpes protects against herpes simplex virus type 2 acquisition. J. Infect. Dis. 194, 42-52 (2006).

-9 Halioua B, Malkin JE. Epidemiology of genital herpes - recent advances. Eur. J. Dermatol. 9, 177-184 (1999).

10 Weiss HA, Buve A, Robinson NJ et al. The epidemiology of HSV-2 infection and its association with HIV infection in four urban African populations. AIDS 15(Suppl. 4), S97-S108 (2001).

11 Corey L, Wald A, Celum CL, Quinn TC. The effects of herpes simplex virus- 2 on HIV-1 acquisition and transmission: a review of two overlapping epidemics. J. Acquir. Immune Defic. Syndr. 35, 435-445 (2004).

- 12 Celum C, Levine R, Weaver M, Wald A. Genital herpes and human immunodeficiency virus: double trouble. Bull. World Health Organ. 82, 447-453 (2004).

13 Celum CL. The interaction between herpes simplex virus and human immunodeficiency virus. Herpes 11(Suppl. 1), 36A-45A (2004).

14 Mbopi-Keou FX, Robinson NJ, Mayaud P, Belec L, Brown DW. Herpes simplex virus type 2 and heterosexual spread of human immunodeficiency virus infection in developing countries: hypotheses and research priorities. Clin. Microbiol. Infect. 9, 161-171 (2003).

15 Wald A. Synergistic interactions between herpes simplex virus type- 2 and human immunodeficiency virus epidemics. Herpes 11, 70-76 (2004).

16 Stamm WE, Handsfield HH, Rompalo AM et al. The association between genital ulcer disease and acquisition of HIV infection in homosexual men. JAMA 260, 1429-1433 (1988).

- 17 Freeman EE, Weiss HA, Glynn JR et al. Herpes simplex virus 2 infection increases HIV acquisition in men and women: systematic review and meta-analysis of longitudinal studies. AIDS 20, 73-83 (2006).
Wald A, Link K. Risk of human immunodeficiency virus infection in herpes simplex virus type 2 -seropositive persons: a meta-analysis. J. Infect. Dis. 185, 45-52 (2002).

19 Cunningham AL, Turner RR, Miller AC, Para MF, Merigan TC. Evolution of recurrent herpes simplex lesions. An immunohistologic study. J. Clin. Invest. 75, 226-233 (1985)

20 Schacker T, Hu HL, Koelle DM et al. Famciclovir for the suppression of symptomatic and asymptomatic herpes simplex virus reactivation in $\mathrm{HIV}$-infected persons. A double-blind, placebocontrolled trial. Ann. Intern. Med. 128, 21-28 (1998).

-21 Palù G, Benetti L, Calistri A. Molecular basis of the interactions between herpes simplex viruses and HIV-1. Herpes 8 , 50-55 (2001).

-22 Albrecht MA, DeLuca NA, Byrn RA, Schaffer PA, Hammer SM. The herpes simplex virus immediate-early protein, ICP4, is required to potentiate replication of human immunodeficiency virus in CD4+ lymphocytes. J. Virol. 63, 18611868 (1989).

-23 Golden MP, Kim S, Hammer SM et al. Activation of human immunodeficiency virus by herpes simplex virus. J. Infect. Dis. 166, 494-499 (1992).

24 Heng MC, Heng SY, Allen SG. Co-infection and synergy of human immunodeficiency virus- 1 and herpes simplex virus-1. Lancet 343, 255-258 (1994).

25 Mosca JD, Bednarik DP, Raj NB et al. Activation of human immunodeficiency virus by herpesvirus infection: identification of a region within the long terminal repeat that responds to a trans-acting factor encoded by herpes simplex virus 1. Proc. Natl Acad. Sci. USA 84, 7408-7412 (1987).

26 Mosca JD, Bednarik DP, Raj NB et al. Herpes simplex virus type-1 can reactivate transcription of latent human immunodeficiency virus. Nature 325, 67-70 (1987).

-27 Schacker T, Ryncarz AJ, Goddard J et al. Frequent recovery of HIV-1 from genital herpes simplex virus lesions in HIV-1infected men. JAMA 280, 61-66 (1998).

-28 Mole L, Ripich S, Margolis D, Holodniy $\mathrm{M}$. The impact of active herpes simplex virus infection on human immunodeficiency virus load. J. Infect. Dis. 176, 766-770 (1997).
-29 Schacker T, Zeh J, Hu H, Shaughnessy M, Corey L. Changes in plasma human immunodeficiency virus type 1 RNA associated with herpes simplex virus reactivation and suppression. J. Infect. Dis. 186, 1718-1725 (2002).

- 30 Serwadda D, Gray RH, Sewankambo NK et al. Human immunodeficiency virus acquisition associated with genital ulcer disease and herpes simplex virus type 2 infection: a nested case-control study in Rakai, Uganda. J. Infect. Dis. 188, 1492-1497 (2003).

-31 Quinn TC, Wawer MJ, Sewankambo N et al. Viral load and heterosexual transmission of human immunodeficiency virus type 1.N. Engl. J. Med. 342, 921-929 (2000).

-32 Gray RH, Wawer MJ, Brookmeyer R et al. Probability of HIV-1 transmission per coital act in monogamous, heterosexual, HIV-1-discordant couples in Rakai, Uganda. Lancet 357, 1149-1153 (2001).

-33 Latif AS, Katzenstein DA, Bassett MT et al. Genital ulcers and transmission of HIV among couples in Zimbabwe. AIDS 3, 519-523 (1989).

-34 Augenbraun M, Feldman J, Chirgwin K et al. Increased genital shedding of herpes simplex virus type 2 in HIV-seropositive women. Ann. Intern. Med. 123, 845-847 (1995).

- 35 Hitti J, Watts DH, Burchett SK et al. Herpes simplex virus seropositivity and reactivation at delivery among pregnant women infected with human immunodeficiency virus-1. Am. J. Obstet. Gynecol. 177, 450-454 (1997).

- 36 Mbopi Keou FX, Gresenguet G, Mayaud P et al. Genital herpes simplex virus type 2 shedding is increased in HIV-infected women in Africa. AIDS 13, 536-537 (1999).

- 37 Mostad SB, Kreiss JK, Ryncarz A et al. Cervical shedding of herpes simplex virus and cytomegalovirus throughout the menstrual cycle in women infected with human immunodeficiency virus type 1 . Am. J. Obstet. Gynecol. 183, 948-955 (2000).

-38 Mostad SB, Kreiss JK, Ryncarz AJ et al. Cervical shedding of herpes simplex virus in human immunodeficiency virus infected women: effects of hormonal contraception, pregnancy, and vitamin A deficiency. J. Infect. Dis. 181, 58-63 (2000)

39 Schacker T, Zeh J, Hu HL, Hill E, Corey L. Frequency of symptomatic and asymptomatic herpes simplex virus type 2 
reactivations among human immunodeficiency virus-infected men. J. Infect. Dis. 178, 1616-1622 (1998).

40 Wald A, Corey L, Cone R et al. Frequent genital herpes simplex virus 2 shedding in immunocompetent women. Effect of acyclovir treatment. J. Clin. Invest. 99, 1092-1097 (1997).

41 WHO. Interim WHO clinical staging of HIVIAIDS and HIVIAIDS Case Definitions for Surveillance (African Region). World Health Organisation, Geneva, Switzerland (2005).

-42 Nagot N, Ouedraogo A, Foulongne V et al. Reduction of HIV-1 RNA levels with therapy to suppress herpes simplex virus. N. Engl. J. Med. 356, 790-799 (2007).

-43 Zuckerman RA, Lucchetti A, Whittington WL et al. Herpes simplex virus (HSV) suppression with valacyclovir reduces rectal and blood plasma HIV-1 levels in HIV-1/ HSV-2-seropositive men: a randomized, double-blind, placebo-controlled crossover trial. J. Infect. Dis. 196, 1500-1508 (2007).

44 Abu-Raddad LJ, Magaret AS, Celum C et al. Genital herpes has played a more important role than any other sexually transmitted infection in driving HIV prevalence in Africa. PLoS ONE 3(5), e2230 (2008).
45 Bacon TH, Levin MJ, Leary JJ, Sarisky RT, Sutton D. Herpes simplex virus resistance to acyclovir and penciclovir after two decades of antiviral therapy. Clin. Microbiol. Rev. 16(1), 114-128 (2003).

46 Gnann JW, Davis MG, Harden EA, Kern ER, and Task Force on HSV Resistance. Acyclovir-resistant HSV from HIV-infected individuals. Population surveillance and in vitro characterization of isolates. Presented at: 38th International Conference Disease Society America. New Orleans, LA, USA, 7-10 September 2000 (Abstract 59).

-47 Gupta R, Hill EL, McClernon D et al. Acyclovir sensitivity of sequential herpes simplex virus type 2 isolates from the genital mucosa of immunocompetent women. J. Infect. Dis. 192(6), 1102-1107 (2005).

48 Cooper DA, Pehrson PO, Pedersen C et al. The efficacy and safety of zidovudine alone or as cotherapy with acyclovir for the treatment of patients with AIDS and AIDS-related complex: a double-blind randomized trial. AIDS 7, 197-207 (1993).

49 Stein DS, Graham NM, Park LP et al. The effect of the interaction of acyclovir with zidovudine on progression to AIDS and survival. Analysis of data in the Multicenter AIDS Cohort Study. Ann. Intern. Med. 121, 100-108 (1994).
Feinberg JE, Hurwitz S, Cooper D et al. A randomized, double-blind trial of valaciclovir prophylaxis for cytomegalovirus disease in patients with advanced human immunodeficiency virus infection. AIDS Clinical Trials Group Protocol 204/Glaxo Wellcome 123-014 International CMV Prophylaxis Study Group. J. Infect. Dis. 177, 48-56 (1998).

-51 Suligoi B, Dorrucci M, Volpi A, Andreoni M, Rezza G. No protective effect of acyclovir on HIV disease progression in a cohort of HSV-2-HIV-infected individuals. Antivir. Ther. 7, 289-291 (2002).

-52 Stanberry LR, Spruance SL, Cunningham AL et al. Glycoprotein-D-adjuvant vaccine to prevent genital herpes. N. Engl. J. Med. 347, 1652-1661 (2002).

\section{Affiliations}

- Antonio Volpi

Department of Public Health, University of Rome Tor Vergata, Via Montpellier 1,

00133 Roma, Italy

Tel.: +390620903440

Fax: +39062090 3441

volpi@uniroma2.it

- Cesare Sarrecchia

Department of Public Health, University of Rome Tor Vergata, Via Montpellier 1, 00133 Roma, Italy

- Pasquale Sordillo Department of Public Health, University of Rome Tor Vergata, Via Montpellier 1, 00133 Roma, Italy 